\title{
Review Article \\ Evaluation of the Medically Complex Living Kidney Donor
}

\author{
Yasar Caliskan and Alaattin Yildiz \\ Division of Nephrology, Department of Internal Medicine, Istanbul School of Medicine, 34390 Istanbul, Turkey \\ Correspondence should be addressed to Alaattin Yildiz, alaattiny@hotmail.com
}

Received 6 November 2011; Accepted 6 March 2012

Academic Editor: Waldo Concepcion

Copyright ( $\odot 2012$ Y. Caliskan and A. Yildiz. This is an open access article distributed under the Creative Commons Attribution License, which permits unrestricted use, distribution, and reproduction in any medium, provided the original work is properly cited.

\begin{abstract}
Due to organ shortage and difficulties for availability of cadaveric donors, living donor transplantation is an important choice for having allograft. Live donor surgery is elective and easier to organize prior to starting dialysis thereby permitting preemptive transplantation as compared to cadaveric transplantation. Because of superior results with living kidney transplantation, efforts including the usage of "Medically complex living donors" are made to increase the availability of organs for donation. The term "Complex living donor" is probably preferred for all suboptimal donors where decision-making is a problem due to lack of sound medical data or consensus guidelines. Donors with advanced age, obesity, asymptomatic microhematuria, proteinuria, hypertension, renal stone disease, history of malignancy and with chronic viral infections consist of this complex living donors. This medical complex living donors requires careful evaluation for future renal risk. In this review we would like to present the major issues in the evaluation process of medically complex living kidney donor.
\end{abstract}

\section{Introduction}

Advances in immunosuppressive therapy, refinement in surgical techniques and in public awareness, altruism, and goodwill have allowed an increase in the number of living donor kidney transplantation; whereby, virtually all biological related, unrelated and medically and psychosocially suitable individuals can be considered as donors [1-6]. Live donor surgery is elective and easier to organise prior to starting dialysis than when the renal donor is a cadaver. In addition, living donor transplants have the advantage of being performed with minimal delay, thereby permitting preemptive transplantation (transplantation prior to dialysis). There is also increasing evidence that patients who undergo preemptive transplantation have improved graft survival compared to those who undergo a period of dialysis before transplantation [7]. Because of superior results with living kidney transplantation, efforts including the usage of "medically complex living donors" are made to increase the availability of organs for donation [8]. The term "complex living donor" was used first by Reese et al. [9] in the International Forum on the Care of the Live Kidney Donor which was held on April 2004 in Amsterdam [7]. The objective of this meeting was to develop international consensus on the standard of care and define the responsibility of the transplant community for the live kidney donor [7-9]. The term "complex living donor" is probably preferred for all suboptimal donors where decision making is a problem due to the lack of sound medical data or consensus guidelines. After this meeting, complex living donors were categorized based on certain risk factors (Table 1). The risk of end-stage renal disease (ESRD) in complex living donors is not clear yet. The evaluation of a potential renal allograft in living donors varies from country to country. In this review we would like to present the major issues in the evaluation process of medically complex living kidney donor.

1.1. Informed Consent. First of all, to avoid conflict of interests, the proposed donor should be carefully evaluated by a physician not involved in the care of the proposed recipient. The physician must confirm that the patient's wish to donate is voluntary. Informed consent is a core value in living kidney donation. Prior to donor nephrectomy, the potential donor must be informed of [10] the following.

(i) The nature of the evaluation process.

(ii) The results and consequences/morbidity of testing, including the possibility that the conditions that may 
TABLE 1: Risk factors associated with complex living donor.

\begin{tabular}{ll}
\hline Type of risk factor & Example \\
\hline Evidence of current renal disease & Hematuria, proteinuria, nephrolithiasis \\
Direct risk for CKD & Hypertension, obesity \\
Reduced nephron mass & Age $\geq 65$ years \\
Genetic risk factor & Family history of ESRD in 1st relative \\
Risk factors for a CKD & Diabetes in first degree relative, impaired fasting glucode \\
Cardiovascular risk factors & Smoking, hyperlipidemia, hypertension \\
Other & Black race, sickle trait \\
Combination of previous factors & Hypertensive black patient \\
\hline
\end{tabular}

CKD: chronic kidney disease and ESRD: end stage renal disease.

be discovered can impact future healthcare, insurability, and social status of the potential donor.

(iii) The risks of operative donor nephrectomy, as assessed after the complete evaluation. These should include, but not be limited to the risk of death, surgical morbidities, changes in health and renal function, impact upon insurability/employability, and unintended effects upon family and social life.

(iv) The responsibility of the individual and the social system in the management of discovered conditions (e.g., if the donor is discovered to have tuberculosis, the donor should undergo treatment, the community has a responsibility to help the donor secure proper care with referral to an appropriate physician).

(v) The expected transplant outcomes (favorable and unfavorable) for the recipient and any specific recipient conditions which may impact upon the decision to donate the kidney.

(vi) Disclosure of recipient specific information which must have the assent of the recipient.

(vii) Alternative renal replacement therapies available to the potential recipient.

Additionally, the potential donor should be capable of understanding the information presented in the consent process.

\section{Clinical Assessment of Medically Complex Living Kidney Donor}

2.1. Elderly Living Donors. Previously, older kidney donors, such as those over 50 years of age, were not considered as suitable. However, the kidneys from such donors are now commonly used if these individuals are in good physical and mental condition and have adequate kidney function. A survey of kidney transplant centers in the United States in 2007 showed that almost 60 percent of centers had no upper-age limit for kidney donors [11]. However, the influence of donor age on the outcome of living donor kidney transplantation is not clear yet. In a retrospective study by Kumar et al. [12], the long-term outcomes of 112 recipients of kidneys from elderly ( $>55$ years) living related donors were compared with 87 recipients who had younger donors ( $<45$ years). The graft and patient survival rates were similar at one year and five years after transplantation between the two groups [12]. There was also no additional morbidity or deterioration of preoperative blood pressure (BP) and renal function at one year in the elderly donors. Another study from the Mayo Clinic by De La Vega et al. [13] also showed similar results. Overall graft survival, patient survival, and death-censored graft survival at three years did not differ significantly between the recipients of older ( $>50$ years) and younger $(<50$ years) living donor kidney grafts [13]. However, there were also studies that reported conflicting results $[14,15]$. In these studies, significantly poorer graft survival rates were found in kidney transplant recipients from elderly donors $[14,15]$. In an analysis of 2.540 living donor kidney transplants at the University of Minnesota, Matas et al. [16] identified donor age greater than 55 years to be a significant risk factor for late graft loss. Advanced age can increase the risk for perioperative complications, but there is no data on longterm outcomes for this specific group in the literature [17].

2.2. Obesity. Obesity $\left(\mathrm{BMI}>30 \mathrm{~kg} / \mathrm{m}^{2}\right)$ in proposed living donors is associated with increased risk for surgical complications as well as future medical problems including diabetes, hypertension, nephrolithiasis, glomerular disease with associated albuminuria or overt proteinuria, and ESRD [1820]. The relative risk for developing ESRD is threefold for a BMI between 30 and $35 \mathrm{~kg} / \mathrm{m}^{2}$ and nearly fivefold for a BMI of $35-40 \mathrm{~kg} / \mathrm{m}^{2}$ [18-20]. The following consensus guidelines regarding obese donors were suggested at the Amsterdam Forum on the Care of the Live Kidney Donor [7].

(i) Patients with a BMI $>35 \mathrm{~kg} / \mathrm{m}^{2}$ should be discouraged from donating, especially when other comorbid conditions are present.

(ii) Obese patients should be encouraged to lose weight prior to kidney donation and should be advised not to donate if they have other associated comorbid conditions.

(iii) Obese patients should be informed of both acute and long-term risks, especially when other comorbid conditions are present.

(iv) Healthy lifestyle education should be available to all living donors. 
According to our transplantation protocol we also advise lifestyle modifications including diet and exercise to our obese donor candidates.

\subsection{Living Donors with Asymptomatic Microhematuria.} Urine dipstick testing in the absence of fever, trauma, menstruation, or intensive exercise should be repeated twice to confirm the presence of microscopic hematuria. Isolated microscopic hematuria (defined as $>3-5$ urinary sediment red blood cells (RBCs)/HPF) may not be a contraindication to donation. RBCs with glomerular origin have a dysmorphic appearance observed by phase-contrast microscopy and automated RBC analysis. Patients with persistent microscopic hematuria should not be considered for kidney donation unless urine cytology and a complete urologic work up are performed [7]. If urological malignancy and stone disease are excluded, a kidney biopsy may be indicated to rule out glomerular pathology such as IgA nephropathy. Additionally, Suzuki et al. reported the presence of latent mesangial IgA deposits in approximately $16 \%$ of biopsies obtained at the time of transplantation from both living and deceased donors otherwise considered healthy [21].

2.4. Living Donors with Proteinuria. Proteinuria greater than $250 \mathrm{mg}$ is a marker of glomerular pathology and renal disease. Proteinuria should be assessed as a standard part of the donor evaluation process. The collection should be repeated and its accuracy checked when the result is abnormal. An overestimate of proteinuria should be suspected if total urine creatinine-to-body-weight ratios are greater than $25 \mathrm{mg} / \mathrm{kg}$ ( $>20 \mu \mathrm{mol} / \mathrm{kg}$ ), especially in those with low muscle mass. Various laboratories have different normal values of quantitated urine protein, but a consensus was reached in Amsterdam forum to conclude that a 24-hour urine protein of $>300 \mathrm{mg}$ is a contraindication to donation [7]. Forum participants also concluded that microalbuminuria determination may be a more reliable marker of renal disease, but its value as an international standard of evaluation for kidney donors has not been determined. The presence of microalbuminuria should preclude donation.

2.5. Hypertensive Living Donors. Hypertension has been considered to be a contraindication in potential renal transplant donors. However, the precise risk to donors who have borderline elevation in BP and those with a family history of hypertension has not been conclusively determined. In general, screening for hypertension in a potential donor includes BP measurement on three separate occasions [7, 22]. According to the guideline by Joint National Committee (JNC 7), BP should preferably be measured by ambulatory blood pressure monitoring (ABPM) [22]. Most transplant centers exclude prospective donors with $\mathrm{BP} \geq 140 / 90 \mathrm{mmHg}$ by $\mathrm{ABPM}$ from donation. An echocardiogram may be considered to evaluate for cardiac hypertrophy in cases with borderline high BP or abnormalities suggesting cardiomegaly or left ventricular hypertrophy on chest radiograph or electrocardiogram, respectively. Some patients with easily controlled hypertension who meet other defined criteria (e.g., $\geq 50$ years of age, GFR $\geq 80 \mathrm{~mL} / \mathrm{min}$, and urinary albumin excretion $<30 \mathrm{mg} /$ day) may represent a low-risk group for development of kidney disease after donation and may be acceptable as kidney donors [7]. The following consensus guidelines regarding hypertensive donors were adopted at the Amsterdam Forum on the Care of the Live Kidney Donor [7].

(i) Patients with a BP $>140 / 90 \mathrm{mmHg}$ by $\mathrm{ABPM}$ are generally not acceptable as donors.

(ii) BP should preferably be measured by ABPM, particularly among older donors ( $\geq 50$ years) and/or those with high office BP readings.

(iii) Some patients with easily controlled hypertension who meet other defined criteria (e.g., $>50$ years of age, GFR $\geq 80 \mathrm{~mL} / \mathrm{min}$, and urinary albumin excretion $<30 \mathrm{mg}$ /day) may represent a low-risk group for development of kidney disease after donation and may be acceptable as kidney donors.

(iv) Donors with hypertension should be regularly followed by a physician.

2.6. Living Donors with Diabetes Mellitus. Type 2 diabetes mellitus is an increasingly common cause of ESRD. When the recipient has diabetes mellitus, the risk of related donors developing diabetes later in life is a major concern. All potential living donors should have a fasting plasma glucose estimation to exclude undiagnosed diabetes or glucose intolerance. Most transplantation centers regard established diabetes mellitus as a contraindication to living donation, and many centers exclude individuals deemed as high risk. Although little is known as to whether single-kidney status would accelerate the progression of diabetic nephropathy, there were experimental studies suggesting the increased risk of developing diabetic nephropathy after nephrectomy [23]. A study by Silveiro et al. [24] also suggested that nephrectomy in a patient with type 2 diabetes might increase the progression of disease and microalbuminuria. Another study by Seaquist et al. [25] reported increased risk for the development of diabetic nephropathy in the relatives of patients with diabetic nephropathy (type I). The protocol in our institution is to advise lifestyle modifications including weight control, diet, exercise, and tobacco and excessive alcohol avoidance to proposed donors with impaired fasting glucose, impaired glucose tolerance, and other risk factors. High risk factors for developing type 2 diabetes include those with a familial history, a BMI of $\geq 30 \mathrm{~kg} / \mathrm{m}^{2}$, women with the history of gestational diabetes, and excessive alcohol use. All other potential living kidney donors related to recipients with diabetes may also have a preexisting increased risk of developing diabetes and diabetic nephropathy [26]. According to International Amsterdam forum on living donor care, individuals with a history of diabetes or fasting blood glucose of $\geq 126 \mathrm{mg} / \mathrm{dL}(7.0 \mathrm{mmol} / \mathrm{L})$ on at least two occasions (or 2 -h glucose with OGTT $\geq 200 \mathrm{mg} / \mathrm{dL}$ $(11.1 \mathrm{mmol} / \mathrm{L}))$ should not donate [7]. However, there was also no comment in this forum about the acceptance of any related donor of a patient with diabetic nephropathy [7]. 
2.7. Living Donors with Renal Stone Disease. A history of urinary tract stones is at least a relative contraindication to donation because urinary system stones tend to recur and may cause obstruction of a solitary kidney. However, renal transplantations performed from donors with kidney stones were reported previously [27-29]. According to Amsterdam forum an asymptomatic potential donor with a history of a single stone may be suitable for kidney donation if [7] he possessed the following characteristics.

(i) No hypercalciuria, hyperuricemia, or metabolic acidosis.

(ii) No cystinuria or hyperoxaluria.

(iii) No urinary tract infection.

(iv) Multiple stones or nephrocalcinosis are not evident on computed tomography (CT) scan.

Contraindications to donation in individuals with urinary stones are (1) nephrocalcinosis on X-ray or bilateral stone disease; and (2) stone types that have high recurrence rates and are difficult to prevent, such as the following.

(i) Cystine stones that have a high rate of recurrence and a need for urologic procedures in the donor.

(ii) Struvite stones or infection stones that are difficult to eradicate, and thus it is not feasible to transplant a kidney with them into an immunosuppressed patient.

(iii) Stones associated with inherited or other systemic disorders, such as primary or enteric hyperoxaluria, distal renal tubular acidosis, and sarcoid because of the probability of a high rate of recurrence and the risk of renal insufficiency.

(iv) Stones in the setting of inflammatory bowel disease with an increased risk of stones particularly after bowel resection, also increased risk of renal insufficiency.

(v) Recurrence while on appropriate treatment (i.e., failed therapy).

Asymptomatic potential donor with current single stone may be suitable if [7]

(i) the donor meets the criteria shown previously for single stone formers and current stone is $\leq 1.5 \mathrm{~cm}$ in size or potentially removable during transplant. An asymptomatic potential donor with no history of calciluria or colic event is found to have a single stone on evaluation may be suitable for kidney donation if [7];

(i) no metabolic abnormality or urinary infection exists and if multiple stones or nephrocalcinosis are not evident on CT.

Incidental renal stone detected by magnetic resonance or computerized tomography renal angiography is relatively common $(7.4 \%)$ in the report from the single center by
Kim et al. [30]. Authors reported that kidneys from donors with small (median radius: $2 \mathrm{~mm}$ ) and nonobstructive stones could be acceptable provided with normal metabolic studies. Another important point is the age of the donor. Younger patients have a longer exposure to risk of recurrence. A stone initially detected in a person older than 50 years is unlikely to recur. In contrast, the risk for stone recurrence is higher in donor candidates aged 25-35 years and must be considered during the evaluation process of donors $[7,29]$.

2.8. Living Donors with History of Malignancy. Kidney donor candidates should be screened for both personal and family history of malignancy. They should undergo standard ageand gender-appropriate screening tests as recommended by national organizations. A prior history of the following malignancies usually excludes live kidney donation [7].

(i) Melanoma, testicular cancer, renal cell carcinoma, choriocarcinoma, hematological malignancy, bronchial cancer, breast cancer, and monoclonal gammopathy [31-34].

A prior history of malignancy usually excludes live kidney donation but may be acceptable if [7].

(i) The specific cancer is curable and the potential transmission of the cancer can reasonably be excluded. Examples include colon cancer (Dukes A, >5 years ago), nonmelanoma skin cancer, or carcinoma in situ of the cervix.

An oncology consultation is also advised to donor candidates with a history of malignancy during the donor evaluation process.

2.9. Living Donors with Chronic Viral Infections. HIV positive status is a contraindication for donation. Donor with a positive hepatitis C Virus (HCV) serology may be only considered for donation to a HCV positive recipient, if the donor PCR is negative, certain genotypes (genotype 4) are treated and eradicated from the donor, and there is no evidence of chronic hepatitis or cirrhosis on liver biopsy. There is no data on live kidney transplantation from HCV positive donors; however, cadaveric renal transplantations from $\mathrm{HCV}$ positive donors to HCV positive recipients were reported [35]. In this report, concerns regarding HCV superinfection if a different $\mathrm{HCV}$ genotype of a positive donor is transmitted to a recipient were also stated [35].

Although the detection of hepatitis B surface antigen (HBsAg) in a potential kidney donor generally excludes the individual from live kidney donation [36]. In our unit, living related kidney transplantations from donors with a positive $\mathrm{HBs}$ Ag to HBV negative recipients were performed with lamivudin prophylaxis when the donor is HBV DNA PCR negative and the recipient's anti-HBS titer is $>100 \mathrm{mIU} / \mathrm{mL}$. Another important point is that even if HBsAg is negative, screening for HBV core total antibody (IgM and IgG) should be performed to exclude low levels of HBsAg and escape mutants of $\mathrm{HBV}$ not detectable by the current screening assays for HBsAg [7]. 
2.10. Living Donors with History of Tuberculosis. Tuberculosis is a common infection of renal transplant recipients in developing countries. The peak incidence is after the first year of transplantation and mortality is considerable [37]. Active Mycobacterium tuberculosis infection is a contraindication for donation because tuberculosis has been transmitted from live kidney donors to their recipients [38]. Although in some centers a past history of pulmonary tuberculosis is a relative contraindication to donation, many kidney transplantations were performed from donors with a past history of pulmonary tuberculosis in several transplant centers as well as in our unit. Some authors suggested that a positive purified protein derivative (PPD) test due to Bacille Calmette-Guérin vaccination may not be helpful to screen a potential live kidney donor. However, a study from our center reported no tuberculosis in renal transplant recipients who had INH prophylaxis for 1 year after transplantation because their and the donors' PPD skin test reading was greater than $10 \mathrm{~mm}$ of induration [37]. In our unit, donation of individuals with a past history of pulmonary tuberculosis is also acceptable. Although there is no clear evidence in the literature for preventing reactivation of tuberculosis and risk of liver toxicity, 1-year INH prophylaxis could be administered to kidney recipients from these donors and recipients with past history of tuberculosis.

Urinary tuberculosis is a contraindication for donation. Additionally, in Amsterdam forum it was suggested that donors previously treated for urinary tuberculosis might have dormant tuberculosis within the kidney and thus remain unsuitable for donation [7].

\section{Conclusion}

Because of superior results with living kidney transplantations, efforts including the use of "medically complex living donors" are made to increase the availability of organs for donation. However, in the evaluation process of these proposed donors we should not forget the following four issues: (1) the risk to the donor must be low, (2) the donor must be fully informed, (3) the decision to donate must be independent and voluntary, and (4) there must be good chance of a successful recipient outcome [39].

\section{References}

[1] J. M. Cecka, “The UNOS scientific renal transplant registry," in Clinical Transplants, J. M. Cecka and P. I. Terasaki, Eds., UCLA Immunogenetics Center, Los Angeles, Calif, USA, 2002.

[2] S. Hou, D. Mital, J. Orlowski et al., "Expanding the kidney donor pool: ethical and medical considerations," Kidney International, vol. 58, no. 4, pp. 1820-1836, 2000.

[3] M. D. Ellison, M. A. McBride, S. E. Taranto, F. L. Delmonico, and H. M. Kauffman, "Living kidney donors in need of kidney transplants: a report from the organ procurement and transplantation network," Transplantation, vol. 74, no. 9, pp. 1349-1351, 2002.

[4] C. L. Davis, "Evaluation of the living kidney donor: current perspectives," American Journal of Kidney Diseases, vol. 43, no. 3, pp. 508-530, 2004.
[5] F. K. Port, D. M. Dykstra, R. M. Merion, and R. A. Wolfe, "Trends and results for organ donation and transplantation in the United States, 2004," American Journal of Transplantation, vol. 5, no. 4, pp. 843-849, 2005.

[6] F. L. Delmonico, E. Sheehy, W. H. Marks, P. Baliga, J. J. McGowan, and J. C. Magee, "Organ donation and utilization in the United States, 2004," American Journal of Transplantation, vol. 5, no. 4, pp. 862-873, 2005.

[7] F. Delmonico, "Council of the transplantation society. A report of the Amsterdam forum on the care of the live kidney donor: data and medical guidelines," Transplantation, vol. 79, supplement 6, pp. S53-S66, 2005.

[8] G. Gopalakrishnan and S. P. Gourabathini, "Marginal kidney donor," Indian Journal of Urology, vol. 23, no. 3, pp. 286-293, 2007.

[9] P. P. Reese, A. L. Caplan, A. S. Kesselheim, and R. D. Bloom, "Creating a medical, ethical, and legal framework for complex living kidney donors," Clinical Journal of the American Society of Nephrology, vol. 1, no. 6, pp. 1148-1153, 2006.

[10] The Ethics Committee of the Transplantation Society, "The consensus statement of the Amsterdam forum on the care of the live kidney donor," Transplantation, vol. 78, no. 4, pp. 491492, 2004.

[11] D. A. Mandelbrot, M. Pavlakis, G. M. Danovitch et al., "The medical evaluation of living kidney donors: a survey of US transplant centers," American Journal of Transplantation, vol. 7, no. 10, pp. 2333-2343, 2007.

[12] A. Kumar, B. S. Verma, A. Srivastava, M. Bhandari, A. Gupta, and R. K. Sharma, "Long-term followup of elderly donors in a live related renal transplant program," Journal of Urology, vol. 163, no. 6, pp. 1654-1658, 2000.

[13] L. S. De La Vega, A. Torres, H. E. Bohorquez et al., "Patient and graft outcomes from older living kidney donors are similar to those from younger donors despite lower GFR," Kidney International, vol. 66, no. 4, pp. 1654-1661, 2004.

[14] H. Toma, K. Tanabe, T. Tokumoto, T. Shimizu, and H. Shimmura, "Time-dependent risk factors influencing the long-term outcome in living renal allografts: donor age is a crucial risk factor for long-term graft survival more than 5 years after transplantation," Transplantation, vol. 72, no. 5, pp. 940-947, 2001.

[15] S. Prommool, G. S. Jhangri, S. M. Cockfield, and P. F. Halloran, "Time dependency of factors affecting renal allograft survival," Journal of the American Society of Nephrology, vol. 11, no. 3, pp. 565-573, 2000.

[16] A. J. Matas, W. D. Payne, D. E. R. Sutherland et al., "2,500 Living donor kidney transplants: a single-center experience," Annals of Surgery, vol. 234, no. 2, pp. 149-164, 2001.

[17] S. R. Kerr, K. J. Gillingham, E. M. Johnson, and A. J. Matas, "Living donors $>55$ years: to use or not to use?" Transplantation, vol. 67, no. 7, pp. 999-1004, 1999.

[18] G. M. Chertow, C. Y. Hsu, and K. L. Johansen, "The enlarging body of evidence: obesity and chronic kidney disease," Journal of the American Society of Nephrology, vol. 17, no. 6, pp. 1501$1502,2006$.

[19] J. K. Heimbach, S. J. Taler, M. Prieto et al., "Obesity in living kidney donors: clinical characteristics and outcomes in the era of laparoscopic donor nephrectomy," American Journal of Transplantation, vol. 5, no. 5, pp. 1057-1064, 2005.

[20] M. Praga, E. Hernandez, J. C. Herrero et al., "Influence of obesity on the appearance of proteinuria and renal insufficiency after unilateral nephrectomy," Kidney International, vol. 58, no. 5, pp. 2111-2118, 2000. 
[21] K. Suzuki, K. Honda, K. Tanabe, H. Toma, H. Nihei, and Y. Yamaguchi, "Incidence of latent mesangial IgA deposition in renal allograft donors in Japan," Kidney International, vol. 63, no. 6, pp. 2286-2294, 2003.

[22] A. V. Chobanian, G. L. Bakris, H. R. Black et al., "National heart, lung, and blood institute joint national committee on prevention, detection, evaluation, and treatment of high blood pressure; national high blood pressure education program coordinating committee. The seventh report of the joint national committee on prevention, detection, evaluation, and treatment of high blood pressure: the JNC7 report," Journal of the American Medical Association, vol. 289, no. 19, pp. 25602572, 2003.

[23] M. W. Steffes, D. M. Brown, and S. M. Mauer, "Diabetic glomerulopathy following unilateral nephrectomy in the rat," Diabetes, vol. 27, no. 1, pp. 35-41, 1978.

[24] S. P. Silveiro, L. A. Da Costa, M. O. Beck, and J. L. Gross, "Urinary albumin excretion rate and glomerular filtration rate in single- kidney type 2 diabetic patients," Diabetes Care, vol. 21, no. 9, pp. 1521-1524, 1998.

[25] E. R. Seaquist, F. C. Goetz, S. Rich, and J. Barbosa, "Familial clustering of diabetic kidney disease. Evidence for genetic susceptibility to diabetic nephropathy," New England Journal of Medicine, vol. 320, no. 18, pp. 1161-1165, 1989.

[26] D. Simmons and M. Searle, "Personal paper: risk of diabetic nephropathy in potential living related kidney donors," British Medical Journal, vol. 316, no. 7134, pp. 846-848, 1998.

[27] R. P. S. Bhadauria, R. Ahlawat, R. V. Kumar, E. S. Srinadh, G. K. Banerjee, and M. Bhandari, "Donor-gifted allograft lithiasis: extracorporeal shockwave lithotripsy with over table module using the lithostar plus," Urologia Internationalis, vol. 55, no. 1, pp. 51-55, 1995.

[28] H. F. Lu, B. Shekarriz, and M. L. Stoller, "Donor-gifted allograft urolithiasis: early percutaneous management," Urology, vol. 59, no. 1, pp. 25-27, 2002.

[29] E. Worcester, J. H. Parks, M. A. Josephson, R. A. Thisted, and F. L. Coe, "Causes and consequences of kidney loss in patients with nephrolithiasis," Kidney International, vol. 64, no. 6, pp. 2204-2213, 2003.

[30] I. K. Kim, J. C. Tan, J. Lapasia, A. Elihu, S. Busque, and M. L. Melcher, "Incidental kidney stones: a single center experience with kidney donor selection," Clinical Transplantation. In press.

[31] G. Morris-Stiff, A. Steel, P. Savage et al., "Transmission of donor melanoma to multiple organ transplant recipients," American Journal of Transplantation, vol. 4, no. 3, pp. 444-446, 2004.

[32] I. Penn, "Transmission of cancer from organ donors," Annals of Transplantation, vol. 2, no. 4, pp. 7-12, 1997.

[33] H. M. Kauffman, M. A. McBride, and F. L. Delmonico, "First report of the united network for organ sharing transplant tumor registry: donors with a history of cancer," Transplantation, vol. 70, no. 12, pp. 1747-1751, 2000.

[34] J. F. Buell, "Use of donors with central nervous system malignancies: proceed with caution [2]," Transplantation, vol. 77, no. 12, pp. 1906-1907, 2004.

[35] J. M. Morales, J. M. Campistol, and B. Dominguez-Gil, "Hepatitis C virus infection and kidney transplantation," Seminars in Nephrology, vol. 22, no. 4, pp. 365-374, 2002.

[36] S. N. Natov and B. J. G. Pereira, "Transmission of viral hepatitis by kidney transplantation: donor evaluation and transplant policies (Part 1: Hepatitis B virus)," Transplant Infectious Disease, vol. 4, no. 3, pp. 117-123, 2002.
[37] A. Yildiz, M. Ş. Sever, A. Türkmen et al., "Tuberculosis after renal transplantation: experience of one Turkish centre," Nephrology Dialysis Transplantation, vol. 13, no. 7, pp. 18721875, 1998.

[38] M. A. Gomha, M. El-Kenawy, and M. Hesham, "Live-donor kidney transplantation: a source for tuberculosis transmission?" African Journal of Urology, vol. 4, p. 62, 1998.

[39] Anonymous, "Ethical issues. UK guidelines for living donor kidney donation," BTS, 1000, 9-14. 


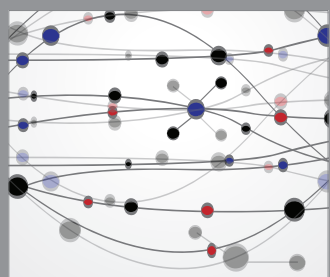

The Scientific World Journal
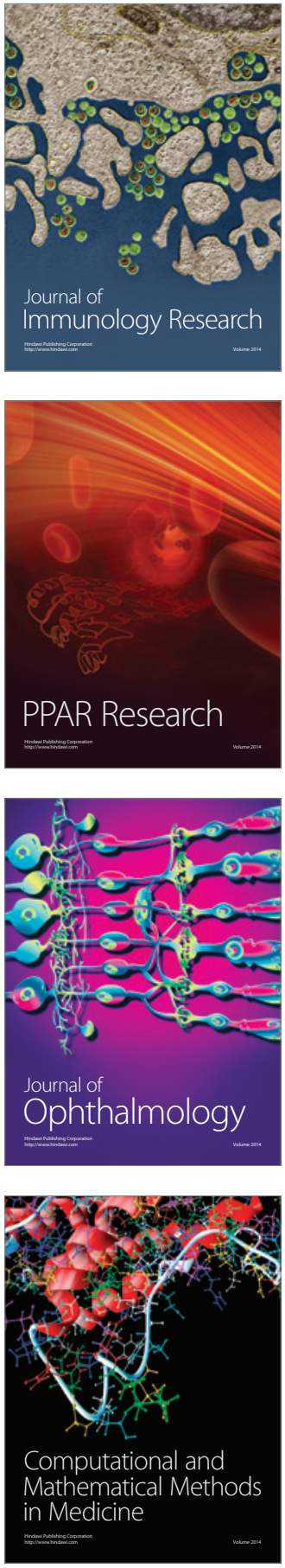

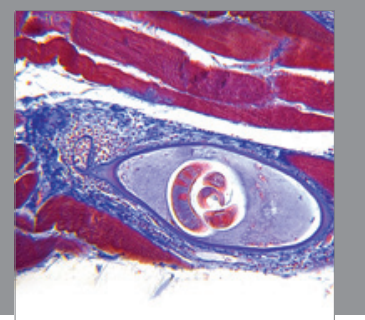

Gastroenterology

Research and Practice
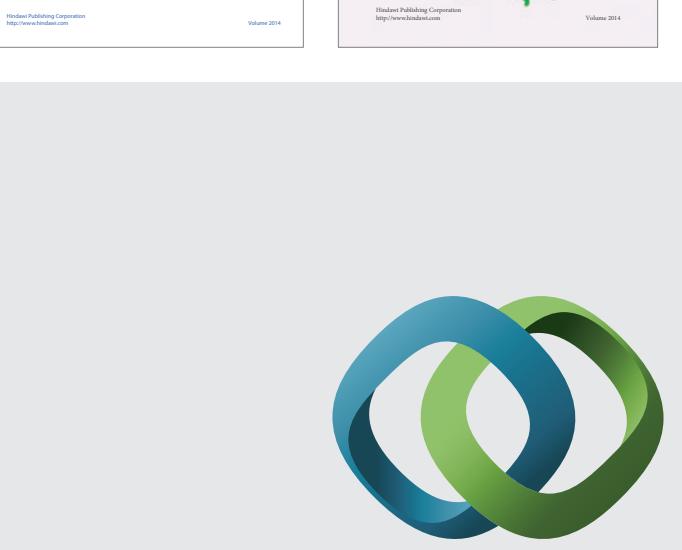

\section{Hindawi}

Submit your manuscripts at

http://www.hindawi.com
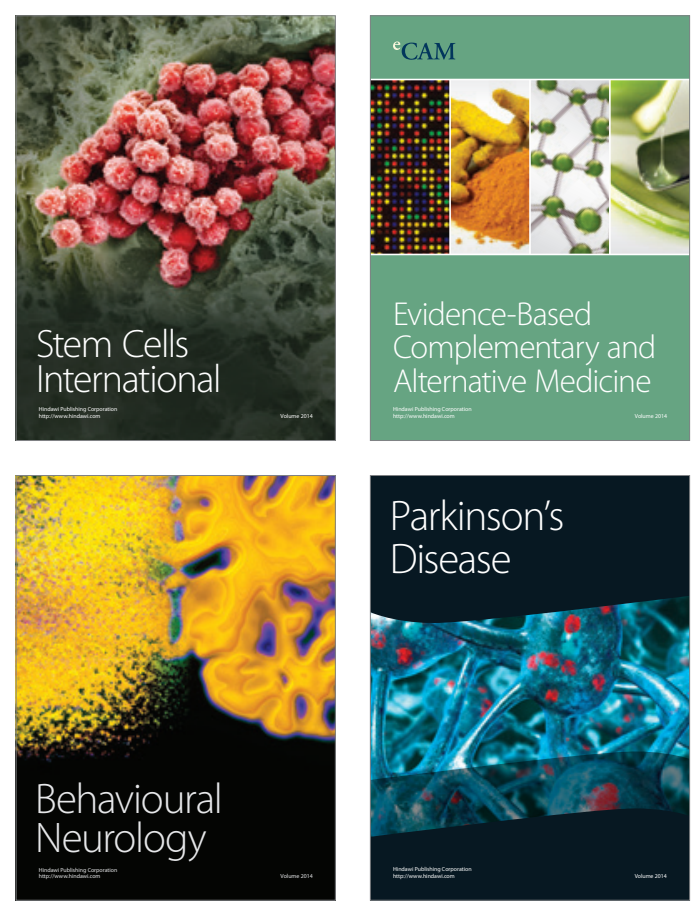

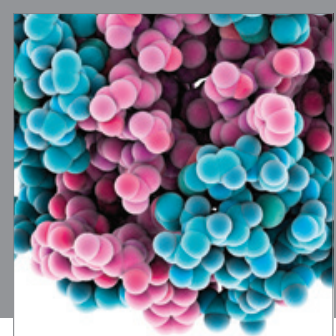

Journal of
Diabetes Research

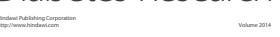

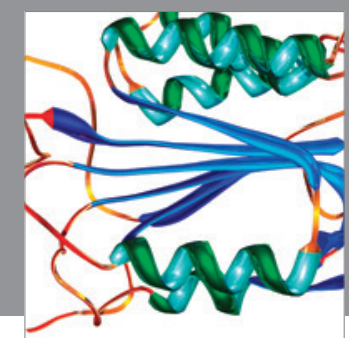

Disease Markers
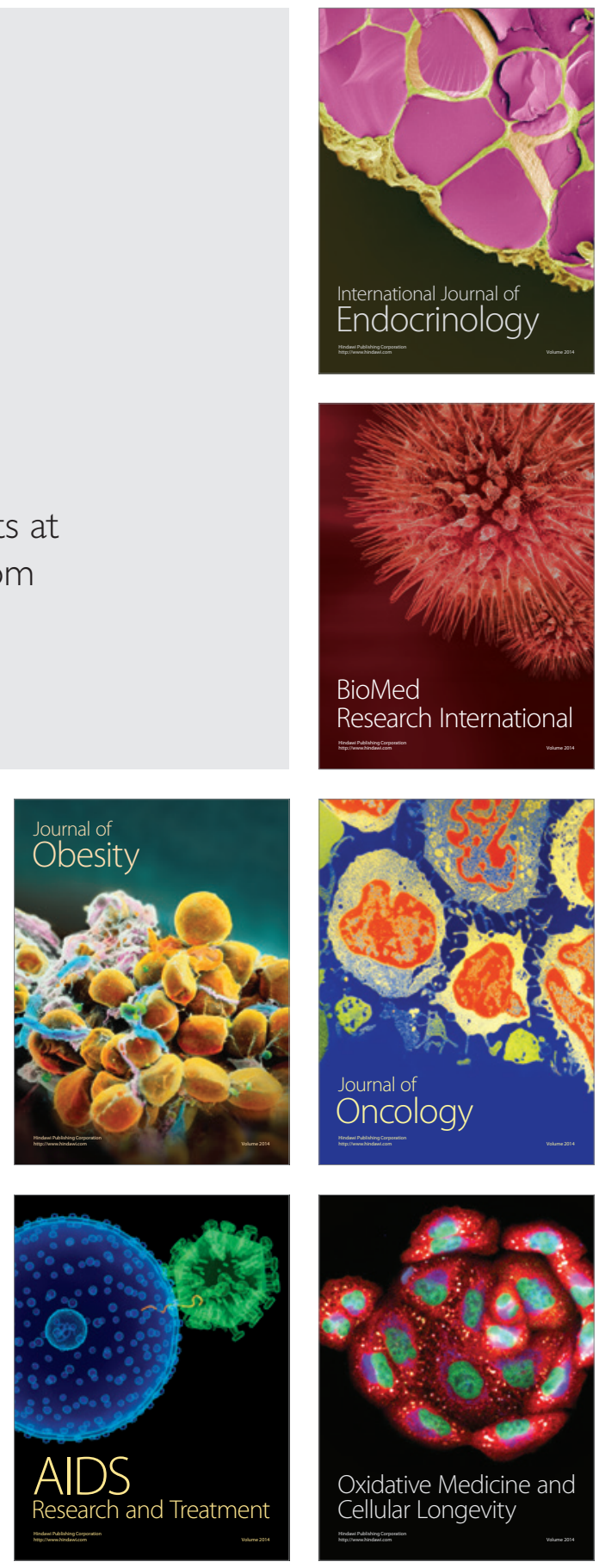